\title{
Peptic ulcer in male factory workers: a survey prevalence, incidence, and aetiological factors
}

\author{
SHUNICHI ARAKI ${ }^{1}$ AND YOSHITAKA GOTO ${ }^{2}$ \\ From the Department of Public Health and Hygiene, ${ }^{1}$ Medical College of Oita, Hazama-cho, Oita, 879-56 \\ Japan, and Tsunohazu Clinic, ${ }^{2}$ Shinjuku, Tokyo, 160 Japan
}

SUMMARY The prevalence of active and inactive peptic ulcer was $23 \%$ in male workers aged $31-60$ at a plastics processing factory in Tokyo. Similarly, the incidence of active and inactive peptic ulcer during one year was $5 \%$ or more. The findings from a case control study suggested that smoking and family history were the major aetiological factors. The incidence and prevalence of peptic ulcer in male factory workers in Japan appear to be higher than elsewhere.

It is difficult to analyse incidence and prevalence rates of peptic ulcer in communities and in industries because the best diagnostic methods (radiological and endoscopic examination) are too expensive and too sophisticated to be applied to general populations. A difficulty also lies in the multiplicity of possible aetiological factors, the distribution of which varies greatly between different study populations. Because of these limitations, few fully reliable morbidity rates for peptic ulcer have been recorded in any country.

In Japan, a mass survey for gastrointestinal disease by photofluorographic methods was begun in the mid $1950 \mathrm{~s}^{1{ }^{2}}$ Since then, the death rate from peptic ulcer has gradually decreased, especially in men aged $40-69,,^{3}$ the major target population for our survey.

At a plastics processing factory in Tokyo, in which pipes and household utensils have been manufactured out of polyvinylchloride and polyethylene, a mass survey using a combination of photofluorography and gastrocamera examination was organised in 1960 by a research group on gastrointestinal disease at the University of Tokyo. ${ }^{4}$ The survey was conducted annually for all workers during 1960-9 and thereafter for workers aged 30 and over. In the course of this survey, we noted that the prevalence of peptic ulcer was higher than is generally expected. A similar observation was recently described among workers in another company in Tokyo, in which electric apparatus and machinery were manufactured. ${ }^{5}$

In the present study we estimated both prevalence and incidence rates of peptic ulcer in our study population. In addition, possible aetiological factors for peptic ulcer were examined by means of a case control investigation. The study was made possible by the active interest of the health and safety organisation in the factory, which led to a high response from the workers to the mass survey for the years 1977 and 1978.

\section{Subjects and methods}

\section{SUBJECTS}

The study population comprised all 348 male workers employed at a plastics processing factory in Tokyo in October 1978, at which time an intensive survey for gastrointestinal disease was organised for all workers. Three hundred and twenty-two male workers $(93 \%)$, warmly encouraged, participated in the survey, and 60 cases of active or inactive peptic ulcer $(19 \%)$ were found during three steps of radiological and endoscopic examination. An intensive survey had also been conducted 12 months previously (October 1977), but only in workers aged 30 and over.

The mass survey was conducted less intensively during the next three years (1979-81) in workers aged 30 and over, and fewer people responded to the examination; only 14 workers were finally diagnosed as new cases of peptic ulcer using the same diagnostic criteria as in 1978. These 14 cases were added to the 60 cases found in 1978 in order to include as many cases as possible for a case control study. The 74 patients were aged 22 to 70 (mean 40 ) years.

The control subjects were workers at the same factory in whom no ulcer had been diagnosed. One control subject was matched to each case for sex (all males), age (same 5-year span), type of work, and job position; the first three factors had priority over the 82 
The mobility of the work force and labour turnover were low at this factory. No serious industrial dispute took place during the years $1977-81$ although the smaller of two trades unions had insistently demanded higher wages and compensation benefits. Periodic statutory medical examination of workers exposed to vinylchloride, lead stearate, and organic solvents disclosed no specific effects of these chemicals on them.

EXAMINATION FOR PEPTIC ULCER

The following three steps in radiological and endoscopic examination for peptic ulcer were taken by one of us (YG), a specialist in gastrointestinal radiology and endoscopy for 16 years: (1) primary screening by barium meal photofluorography in five prearranged positions: prone, supine right anterior oblique, supine posteroanterior, upright right anterior oblique, and upright anteroposterior; (2) fluoroscopic examination by means of spot film compression radiography, barium and air double-contrast study, and filling film study; (3) endoscopic examination for final diagnosis. Cases with an ulcer crater in the stomach or duodenum were diagnosed as active; cases with evidence of an ulcer scar in the stomach or duodenum were diagnosed as inactive. Criteria for the radiological diagnosis of gastric ulcer scar were combinations of some of the following: radiating folds, rigid or straightened contour, shortening of the lesser curvature, indentation of the greater curvature, and other signs in the absence of an ulcer crater in the stomach. Radiological diagnosis of duodenal ulcer scar was made when the duodenal bulb was deformed without evidence of an ulcer crater. Similarly, the endoscopic diagnosis was made when ill demarcated reddening or pale whitish discolouration was present, occasionally with radiating folds towards it, but no slough-covered ulcer crater was found. The evaluation of these findings is not difficult to trained specialists; we believe, therefore, that the diagnosis of active and inactive ulcers in the present study was valid and reproducible.

\section{EXAMINATION OF AETIOLOGICAL FACTORS}

In all, 32 possible aetiological factors of peptic ulcer were selected for a case control study. All factors were assessed at interview between one of us (SA) and the subjects each year just after the examination for peptic ulcer. The subjects were informed of their health status (case or control) after the interview. The proportions for each factor were compared between cases and controls, and differences were assessed by means of the chi squared test (paired comparison) and the matched odds ratio. The equations for the calculation were: $\chi^{2}(1 \mathrm{df})=(\mathrm{r}-\mathrm{s} \vdash-1)^{2} /(\mathrm{r}+\mathrm{s})$, where $\mathrm{r}$ and $\mathrm{s}$ are the numbers with the factor in cases only and controls only, respectively; odds ratio $=r / s$. For a quantitative comparison of factors between cases and controls, the $t$ test (paired comparison) was used. No allowance was made for simultaneous inference in multiple comparisons.

\section{Results}

PREVALENCE RATE

Prevalence rates of peptic ulcer by age group are shown in table 1 . The rate was $23 \%$ for active and inactive ulcer in workers aged $31-60$, including $8 \%$ for active ulcer. Of the total prevalence (active and inactive) in this age group, $43 \%$ were classified as gastric, $41 \%$ as duodenal, and $16 \%$ as gastroduodenal.

\section{INCIDENCE RATE}

As a mass survey for gastrointestinal disease had also been conducted in 1977 in workers aged 30 and over, the incidence rate of peptic ulcer during 1977-78 (12 months) could be estimated only in men aged 31-60. Among the 209 workers in this age group, nine cases of active and inactive peptic ulcer were newly found in 1978; another 40 cases were "old" cases already diagnosed as peptic uIcer in 1977. In a small number of workers, peptic ulcer might have been either present in October 1977 or newly developed thereafter, then healed without trace by October 1978. Thus, at least 5\%, that is, nine (or more) of 169 (209 minus 40, or less) workers, developed a new peptic ulcer during the one year period. Similarly, the incidence rate for active peptic ulcer was probably $1 \%$ or more and that for active and inactive gastric ulcer was $3 \%$ or more. It was difficult to estimate the incidence rates between 1978 and 1981 because a smaller number of workers participated in each step of the radiological and endoscopic examination for the years 1979-81; therefore, the exact number and age of all the participants were difficult to identify.

\section{AETIOLOGICAL FACTORS}

Among the $\mathbf{3 2}$ factors examined, two-ulcer in first or second degree relatives and smoking-were significantly more frequent in 74 cases of active and inactive peptic ulcer than in the matched controls; conversely, alcohol ingestion was significantly less frequent (table 2). These factors were not significantly associated with each other in either cases or matched controls $\left(\chi^{2}\right.$ test, $\left.p>0 \cdot 05\right)$. When specific types of peptic ulcer were examined, significantly more tobacco was smoked by those with active gastric ulcer [26 \pm 11 (SD) cigarettes/day] than by the matched controls (10 \pm 9 cigarettes/day). Ulcer in 
Table 1 Workers examined and prevalence of peptic ulcer in 1978

\begin{tabular}{|c|c|c|c|c|c|c|c|c|c|}
\hline \multirow{2}{*}{$\begin{array}{l}\text { Age } \\
(y r)\end{array}$} & \multirow{2}{*}{$\begin{array}{l}\text { No of } \\
\text { workers } \\
\text { examined }\end{array}$} & \multicolumn{2}{|c|}{ (1) Gastric ulcer } & \multicolumn{2}{|c|}{ (2) Duodenal ulcer } & \multicolumn{2}{|c|}{ (3) Gastroduodenal ulcer } & \multicolumn{2}{|c|}{$(1)+(2)+(3)$} \\
\hline & & Active & Inactive & Active & Inactive & Active & Inactive & Active & Inactive \\
\hline $19-30$ & 109 & 1 & 6 & 0 & 1 & 0 & 2 & $1[1]$ & $10[9]$ \\
\hline $31-60$ & 209 & $7^{*}[3]$ & $14[7]$ & $8+[4]$ & $12[6]$ & $1[0 \cdot 5]$ & $7[3]$ & $16[8]$ & $49[23]$ \\
\hline $61-70$ & 4 & 0 & 0 & 1 & 0 & 0 & 0 & 1 & 1 \\
\hline Total & 322 & 8 & 20 & 9 & 13 & 1 & 9 & $18[6]$ & $60[19]$ \\
\hline
\end{tabular}

* One active gastric ulcer with inactive duodenal ulcer is included.

† One active duodenal ulcer with inactive gastric ulcer is included.

[] Prevalence $\%$.

first or second degree relatives and a habit of eating at irregular intervals were significantly more frequent in active and inactive duodenal ulcer [odds ratio: $\infty$ $(6 / 0)$ and $14 \cdot 0$, respectively].

\section{Discussion}

Smoking and heredity have been positively related to peptic ulcer in many studies in western countries. ${ }^{6-8}$ A possible pathogenic mechanism, by which smoking may promote peptic ulcer, has been described as follows: in smokers with ulcer there is hypersecretion of pepsin 1, incompetence of the pyloric sphincter, and decreased secretion of pancreatic bicarbonate. ${ }^{9}$ In consequence, the gastric mucosa may be affected by pepsin 1 more directly than the duodenal mucosa, and the damage increased by reflux of jejunal contents. This may support the association of smoking with peptic ulcer (especially gastric ulcer) in our study. Similarly, there is evidence for a genetic influence: ${ }^{6}$ genetic markers, such as hyperpepsinogenaemia 1 and blood group 0 , are more common in subjects with duodenal ulcer, and there is a high frequency of gastric and duodenal ulcers in first degree relatives of ulcer patients. This may support the association of family history with peptic (especially duodenal) ulcer in our study, though it is difficult to exclude biased reporting of family history.

On the other hand, other factors, such as alcohol, coffee, and mental stress, have not been shown to be related to peptic ulcer in many studies. ${ }^{6-810}$ The inverse relation of alcohol consumption to peptic ulcer in our study may represent changes in lifestyle subsequent to the development of the ulcer. Similarly, no significant association of frustration at work or in the family (assessed by the Cornell Medical Index-Health Questionnaire and by interview) with peptic ulcer may simply illustrate the difficulty of testing psychosocial factors by the usual epidemiological methods. ${ }^{10}$

We failed to find any well documented epidemiological report of the morbidity rate of peptic ulcer. In community surveys, attention is usually focused on gastric cancer resulting in a low detection rate of peptic ulcer (table 3). ${ }^{112}$ Thus, it is natural that the detection rate is higher in an industry (table 3 ) in which gastric cancer is rarely detected and more attention is paid to peptic ulcer. The prevalence of active ulcer in our factory $(8 \%)$ was nearly equal to the rate (about 9-11\%) reported in another company ${ }^{5}$ (tables 1 and 3 ). The diagnostic methods

Table 2 Three factors significantly associated with peptic ulcer, their distribution (and values) in 74 cases of peptic ulcer and matched controls, and matched odds ratio*

\begin{tabular}{|c|c|c|c|c|c|}
\hline \multirow[b]{2}{*}{ Factors } & \multicolumn{2}{|l|}{ Cases } & \multicolumn{2}{|l|}{ Controls } & \multirow{2}{*}{$\begin{array}{l}\text { Odds } \\
\text { ratio }\end{array}$} \\
\hline & No (\%) & Mean $(S D)$ & No (\%) & Mean $(S D)$ & \\
\hline Ulcer in 1st or 2 nd degree relatives & $13(18)$ & & $2(3)$ & & $12.0 \ddagger$ \\
\hline $\begin{array}{l}\text { Smoking } \\
\text { (cigarettes/day) }\end{array}$ & $63(85)$ & $20(12)^{* *}$ & $48(65)$ & $14(15)^{* *}$ & $2.7 t$ \\
\hline $\begin{array}{l}\text { Alcohol ingestion } \\
\text { (ml of } 100 \% \text { alcohol/day) }\end{array}$ & $40(54)$ & $21(24)$ & $56(76)$ & $28(24)$ & $0.3 \ddagger$ \\
\hline
\end{tabular}

*All other factors examined (29 factors), ie (a) genetic and somatic factors (blood groups, height and body weight), (b) personality and emotional factors (CMI test and personalities), (c) coffee and eating habits, $(d)$ occupational factors (shift work, overtime work, and frustration at work), and (e) family and other factors (school career, marital status, habit of car-driving, frustration in family, etc), were not significantly associated with peptic ulcer.

,+ \pm Significantly different from 1.0 at $p<0.05$ and 0.01 , respectively.

** Significantly different at $p<0.05$ by paired comparison (t test). 
Table 3 Reports of prevalence ofpeptic ulcer in men in Japan are also due to Dr K Murata and Miss S Yasumi,

\begin{tabular}{lllll}
\hline $\begin{array}{l}\text { Prevalence } \\
(\%)\end{array}$ & $\begin{array}{l}\text { Criteria } \\
\text { of ulcer }^{*}\end{array}$ & $\begin{array}{l}\text { Investigative } \\
\text { procedure }^{*}\end{array}$ & Age (yr) & $\begin{array}{l}\text { Reference } \\
\text { No }\end{array}$ \\
\hline $\begin{array}{l}\text { Community: } \\
2 \cdot 3\end{array}$ & A (\& I) & P & All & 11 \\
8 & A \& I & P & All & 12 \\
$\begin{array}{l}\text { Industry: } \\
17 \div\end{array}$ & A (\& I) & P,E & 40 and over & 5 \\
23 & A \& I & P,F,E & $31-60$ & Present study \\
\hline
\end{tabular}

* $\mathrm{A}=$ active ulcer, $\mathrm{I}=$ inactive ulcer.

$\doteqdot P=$ routine photofluorography, $F=$ fluoroscopy, $E=$ endoscopy.

$\doteqdot$ The rate of active ulcer is about $1 / 2$ to $2 / 3$ of this value (a mean in 13 -yr surveys), ie $9-11 \%$.

were similar in these two studies since both authors (YG and TM) were members of the same research group at the University of Tokyo. Working conditions in the two manufacturing industries such as management structure, health and safety organisation, shiftwork, and wages were also similar although they were different from each other in types of production. These findings suggest that the prevalence and incidence of peptic ulcer in Japanese factory workers may be truly high.

A lower prevalence of peptic ulcer has been reported in many other countries: ${ }^{13}$ USA, $2 \cdot 5 \%$; England (London), 5·2\%; Australia (Melbourne), $7 \cdot 2 \%$; and Scotland (Aberdeen), 9.9\%. The incidence estimated in the USA (approximately $0 \cdot 23 \%$ per year $)^{14}$ is lower than ours. However, the survey methods differed in these two countries; and the results are not directly comparable. Further studies will be required to clarify the position.

We thank Professor J C McDonald, School of Occupational Health, McGill University, and Dr M Fujino, Yamanashi University School of Medicine, for their critical reviews of this manuscript. Thanks

Medical College of Oita, for their assistance in the statistical work and preparation of the manuscript.

\section{References}

${ }^{1}$ Irie H, Kadota H. Early detection of gastric cancer by photofluorography.Jpn Med J 1953; No 1513: 5-7. (In Japanese.)

${ }^{2}$ Kurokawa T, Saito T. Early diagnosis of gastric cancer. Saishin-Igaku 1956; 11: 167-80. (In Japanese.)

${ }^{3}$ Yamada M, Araki S, Murata K. A statistical analysis of the decrease in death rate from peptic ulcer during twenty five years (1950-1975) after the Second World War in Japan. Human Ecology and Race Hygiene 1981; 47: 207-12. (In Japanese with English abstract.)

${ }^{4}$ Sakita T, Ashizawa S, Utsumi Y, et al. A mass survey by gastrocamera. Jpn J Clin Med 1960; 18: 14-6. (In Japanese.)

${ }^{5}$ Miwa T. Some observations on duodenal ulcer. In: Miwa T, ed. A study of duodenal ulcer. Tokyo: Igaku Shoin, 1982: 1-15. (In Japanese.)

${ }^{6}$ Grossman MI. Peptic ulcer: the pathophysiological background. Scand J Gastroenterol (Suppl) 1980; 15: $7-16$.

${ }^{7}$ Isenberg JI. Peptic ulcer: epidemiology, nutritional aspects, drugs, smoking, alcohol, and diet. Curr Concepts Nutr 1980; 9: 141-51.

${ }^{8}$ Friedman GD, Siegelaub AB, Seltzer CC. Cigarettes, alcohol, coffee and peptic ulcer. New Engl J Med 1974; 290: $469-73$.

${ }^{9}$ Taylor WH, Walker V. Smoking and peptic ulceration. $J$ Roy Soc Med 1980; 73: 159-61.

${ }^{10}$ Groen JJ. Work and peptic ulcer. In: Levi L, ed. Society, stress, disease Vol 4. New York: Oxford University Press, 1981: 201-11.

${ }^{11}$ Hattori K. National gastric-mass-survey report (1978). Gastric cancer (Japanese Society of Gastric-Mass-Survey) 1980; No 48: 55-66. (In Japanese.)

${ }^{12}$ Hisamichi S, Sugawara N, Yamagata S. Epidemiological comments on peptic ulcer. Naika 1979; 44: 848-53. (In Japanese.)

${ }^{13}$ Langman MJS. Epidemiology of peptic ulcer. In: Bockus HL, ed. Gastroenterology Vol 1, Third ed. Philadelphia: WB Saunders, 1974: 611-8.

${ }^{14}$ Sturdevant RAL, Walsh JH. Duodenal ulcer. In: Sleisenger MH, Fordtran JS, eds. Gastrointestinal disease: pathophysiology, diagnosis, management. Philadelphia: WB Saunders, 1978: 840-60. 
Parents' and professionals' attitudes to measles immunisation

A Lakhani, R Morris, M Morgan, C Dale, and M Vaile Department of Community Medicine, St Thomas' Hospital Medical School, London

The evaluation of the South Manchester Family Worker Scheme

B Spencer and J Morris

Department of Epidemiology and Social Research, University Hospital of South Manchester, Manchester
Ethnic minorities and the cost of care in the community M R Baker and E E M Kernohan

Clinical Epidemiology Research Unit, University of Bradford

During the meeting members of the Open University gave a guest presentation entitled "Health and Disease: A New Open University Course”.

\section{Corrections}

In the paper by Shunichi Araki and Yoshitaka Goto $(1985 ; 39: 82-5)$ the heading of the last column in Table 1 should read 'Total'.

In the paper by A Menotti and F Seccareccia (1985; 39: 325-9) the third line of Table 6 should read: Myocardial infarction $y=7 \cdot 60-1 \cdot 88 \mathrm{FA}+1 \cdot 82 \mathrm{JR}$ 0.73 . The footnote to Table 6 should read: ${ }^{* *} \mathrm{p}<0 \cdot 01$. In the left-hand column of page 328 , line 34 should read: (2) All coefficients of job responsibility are negative except that concerning chronic bronchitis and myocardial infarction. 